\title{
SOCIJALNO POŽELJNO ODGOVARANJE I VRIJEME LATENCIJE U KONTEKSTU SELEKCIJSKOGA POSTUPKA PRI ZAPOŠLJAVANJU ${ }^{3}$
}

\section{SAŽETAK}

Socijalno poželjno odgovaranje definira se kao sistematska tendencija davanja pretjerano pozitivnih samoprocjena i često se potvrđuje prilikom selekcijskog postupka. Cilj je ovog istraživanja bio utvrditi postoji li razlika u davanju socijalno poželjnih odgovora i u brzini odgovaranja između osoba koje se prijavljuju na natječaj za posao i kontrolne skupine ispitanika. Uzorak se sastojao od ukupno 252 ispitanika. Eksperimentalna skupina brojila je 94 kandidata koji se za posao prijavljuju na profesionalnoj društvenoj mreži (www.linkedin.com) i jednom domaćem portalu (www.bika.net), na kojem se oglašavaju slobodna radna mjesta, dok je u kontrolnoj skupini bilo 158 sudionika koji su odgovarali na ista pitanja kao i kandidati za posao. Web-upitnik se sastojao od ukupno 36 čestica preuzetih iz Eysenckove skale laži i Paulhusove skale samozavaravanja. Multivarijantnom analizom varijance ustanovljeno je da kandidati prilikom prijave za posao daju više socijalno poželjnih odgovora te da odgovaraju sporije u odnosu na sudionike iz kontrolne grupe. Rezultati diskriminantne analize sugeriraju da bi se vrijeme latencije moglo koristiti kao indikator socijalno poželjnog odgovaranja. Razmotrene su implikacije i prijedlozi za buduća istraživanja.

Ključne riječi: socijalno poželjno odgovaranje, selekcijski postupak, vrijeme latencije, web-upitnik

\section{UVOD}

Upotreba upitnika ličnosti koji se temelje na samoprocjeni kandidata česta je u organizacijskoj praksi, pogotovo u kontekstu selekcije za posao. Takav postupak, međutim, ima određenih nedostataka, a jedan od ključnih je socijalno poželjno odgovaranje, koje se definira kao sustavna tendencija davanja pretjerano pozitivnih samoprocjena (Paulhus, 2002). Takvo iskrivljavanje odgovora predstavlja problem, osobito pri testiranju za posao, jer motivacija za kreiranje povoljne samoprezentacije u selekcijskoj je situaciji osobito visoka, a istraživanja pokazuju da ljudi mogu prepoznati na što se odnosi pojedina čestica upitnika i, prema tome, prilagoditi svoje odgovore, uz malu vjerojatnost da će biti uhvaćeni u laži (Proroković et al., 2008). Predmet istraživanja ovog rada definiran je kao usporedba sadržaja odgovora na socijalno poželjna pitanja te brzine odgovaranja između skupine kandidata koji se prijavljuju za posao i kontrolne skupine sudionika.

\footnotetext{
Mag. psych., Filozofski fakultet u Rijeci, Sveučilišna avenija 4, 51000 Rijeka, Hrvatska. E-mail: matejfiskus@gmail.com

2 Dr. sc., poslijedoktorand, Filozofski fakultet u Rijeci, Sveučilišna avenija 4, 51000 Rijeka, Hrvatska.

E-mail: domagoj.svegar@ffri.uniri.hr

3 Datum primitka rada: 10. 10. 2017.; datum prihvaćanja rada: 15. 12. 2017.
} 
Socijalno poželjno odgovaranje može se identificirati različitim mjernim skalama, od kojih su među najčešće korištenima Eysenckova skala laži iz EPQ-upitnika, poznatija kao L-skala (Lojk, 1979) te skala samozavaravanja i upravljanja dojmovima (Paulhus, 2002).

Skala laži mjeri disimulaciju kao sumu pozitivnih odgovora na pitanja koja predstavljaju socijalno poželjne tvrdnje, a koje su zapravo vrlo rijetke (npr. Kao dijete uvijek sam, bez gunđanja, poslušao/ la na prvu riječ. ili Uvijek sam spreman/na priznati pogrešku koju sam učinio/la.) i negativnih odgovora na pitanja koja predstavljaju socijalno nepoželjne tvrdnje, ali su u praksi vrlo česte (npr. Ponekad se volim malo hvaliti pred drugima. ili Najmanje jednom sam o nekome rekao/la nešto loše ili bezobrazno.).

Za razliku od Eysenckove jednodimenzionalne skale, Gur i Sacheim (1979) definirali su dva faktora socijalno poželjnog odgovaranja, samozavaravanje i zavaravanje drugih. Samozavaravanje su definirali kao nerealno pozitivne samoprocjene u koje su ispitanici uvjereni, a manifestiraju se nijekanjem relativno čestih ponašanja koje je neugodno priznati. S druge pak strane, zavaravanje drugih opisali su kao svjesno i namjerno iskrivljavanje samoprocjena u svrhu zavaravanja publike kojoj se osoba predstavlja. Njihov je model razradio Paulhus (2002), koji je zadržao faktor samozavaravanja, dok je umjesto faktora zavaravanja drugih uveo sličan konstrukt koji naziva upravljanje dojmovima.

Istraživanja koja proučavaju modele i teorije iskrivljavanja odgovora na upitnicima ličnosti moguće je podijeliti u dvije skupine: jednu, koja obuhvaća istraživanja u simuliranim uvjetima, i drugu, koja se odnosi na situacije stvarne profesionalne selekcije. U okviru istraživanja u simuliranim uvjetima uspoređuju se odgovori na upitnicima ličnosti u situaciji iskrenog odgovaranja i uvjeta u kojem su ispitanici instruirani da se prikažu u najboljem svjetlu ili „odglume“ zadane osobine ličnosti. U jednom od takvih istraživanja Krahé (1989) je ustanovila da kod ljudi postoji sklonost naglašavanja određenih karakteristika ličnosti koje su u skladu s njihovom percepcijom idealnog zaposlenika. Do iskrivljavanja odgovora dolazi i u situacijama stvarne profesionalne selekcije iako u nešto manjoj mjeri (Smith, Ellingson, 2002). Profili ličnosti dobiveni u selekcijskim situacijama pozitivniji su nego oni već zaposlenih kandidata (Rosse et al., 1998). U skladu s tim nalazom Proroković et al. (2008) pokazali su kako ispitanici u selekcijskoj situaciji ostvaruju značajno viši rezultat na skali laži u odnosu na ispitanike iz neselekcijskog uvjeta.

Proces odgovaranja na upitnike samoprocjene uključuje nekoliko faza: interpretaciju pitanja, doziv informacija o svom ponašanju ili osobinama, stvaranje slike ili reprezentacije ponašanja, oblikovanje i davanje odgovora (Sudman et al., 1996). Taj slijed procesa nije, međutim, uvijek jednak i ponekad nije nužno da svaki od ovih procesa bude prisutan, a upravo su na temelju tog saznanja proizašle međusobno suprotstavljene hipoteze o vremenu latencije kod socijalno poželjnog odgovaranja Holtgraves (2004). Najstarija od njih, koju je utemeljila Nowakowska (1970), podrazumijeva kako će ispitanici u situaciji kada su motivirani davati socijalno poželjne odgovore (npr. selekcijski postupak), odgovarati sporije jer kognitivno procesiranje tijekom odgovaranja tada obuhvaća doziv informacija, oblikovanje odgovora i evaluaciju odgovora. Potpuno suprotna hipoteza predviđa kraće vrijeme latencije za ispitanike koji su motivirani prikazati se pretjerano dobrima. Ona nalazi uporište u rezultatima koje su dobili Leary i Kowalski (1990), koji tvrde da 
ispitanici u takvoj situaciji uopće ne dozivaju točne informacije o svom ponašanju ili osobinama, već produciraju odgovor na temelju implikacija koje će imati odgovor. Treća hipoteza pretpostavlja da ispitanici dozivaju informacije, ali na pristran (heurističan) način, odnosno selektivno dozivaju informacije koje ostavljaju pozitivan dojam o njima (Zuckerman et al., 1995).

U jednom od eksperimentalnih klasika ovog područja Holden et al. (1992) studentima su dali upitnike ličnosti u tri neovisne situacije: situaciji iskrenog odgovaranja, situaciji uputom poticanog uljepšavanja sebe i situaciji uputom poticanog prikazivanja sebe u negativnom svjetlu. Ispitanici su u situaciji uljepšavanja sporije davali potvrdne odgovore na čestice koje nisu socijalno poželjne $u$ odnosu na iskrene ispitanike i ispitanike u situaciji prikazivanja u negativnom svjetlu. Za razliku od njih, ispitanicima u situaciji prikazivanja u negativnom svjetlu trebalo je više vremena za davanje socijalno poželjnih odgovora nego ispitanicima u ostale dvije situacije. Na temelju tih nalaza Holden et al. (1992) predložili su model prema kojem odgovori koji nisu kongruentni s motivacijskom shemom ispitanika iziskuju više vremena.

Holtgraves (2004) je u kasnijem istraživanju analizirao ukupne rezultate i njima pripadajuća vremena latencije na skalama samozavaravanja i upravljanja dojmovima kod skupina ispitanika različito motiviranih za davanje socijalno poželjnih odgovora. Pretpostavio je da će ispitanici na skali upravljanja dojmovima namjerno i svjesno davati socijalno poželjne odgovore i samim time sukladno modelu Holdena et al. (1992) sporije odgovarati, dok će na skali samozavaravanja rabiti pristran doziv informacija, koji je zbog spomenutih razloga brži, i zbog toga imati kraće vrijeme latencije. Upravo je takve rezultate i dobio: vrijeme latencije za skalu samozavaravanja bilo je kraće u svim eksperimentima koje je proveo.

Parmač et al. (2009) testirali su model disimulacije Holdena et al. (1992) na nezavisnim uzorcima ispitanika u dvije motivacijske situacije: iskreno odgovaranje i uljepšavanje sebe, koje su operacionalizirali davanjem različitih uputa. Dobiveni rezultati pokazuju da su ispitanici koji su dobili uputu da se prikažu u što je moguće boljem svjetlu imali više rezultate na skalama ekstraverzije (društvenosti), ugodnosti, savjesnosti, emocionalne stabilnosti otvorenosti te na obje skale socijalne poželjnosti. Na skalama socijalne poželjnosti nije bilo razlike između iskrenih ispitanika $i$ ispitanika u situaciji uljepšavanja u vremenu latencije za socijalno poželjne odgovore, ali su se na skali upravljanja dojmovima skupine razlikovale. Ispitanicima u situaciji uljepšavanja trebalo je više vremena da daju odgovor koji nije socijalno poželjan nego što je vremena trebalo iskrenim ispitanicima. Prema tome, Parmač et al. (2009) samo su djelomično potvrdili Holdenov model jer je razlika u vremenu latencije postojala samo za odgovore koji nisu socijalno poželjni.

Testiranje na internetu ima neke evidentne prednosti, poput fleksibilnosti u pogledu mjesta i vremena testiranja, ali i određene nedostatke, npr. nemogućnost razjašnjenja nejasnoća, nemogućnost kontrole ispitanika, nepredviđena ometanja u okolini i slično. Također, moguće su i tehničke poteškoće $s$ računalnom opremom koju posjeduje ispitanik, npr. spor modem, neprikladan ekran, spora veza na internet. Osim navedenih prednosti i nedostataka praktične prirode, ključno je pitanje istovjetnosti rezultata prikupljenih računalnim putem i onih dobivenih tradicionalnim testiranjem pomoću papira i olovke. 
Usporedivost podataka prikupljenih u selekcijskim situacijama pomoću online-anketa i tradicionalnom metodom papira i olovke istraživali su Bartram i Brown (2004) i zaključili da je internalna struktura korištenih upitnika stabilna kroz različite načine primjene. Ployhart et al. (2001) su u sličnom istraživanju na velikom uzorku od gotovo 5000 sudionika, koji su se prijavljivali za posao ustanovili da se u oba načina primjene selekcijske procedure rezultati nisu statistički značajno razlikovali. Rezultati Salgada i Moscosa (2003) također idu u prilog činjenici da nema značajnih razlika ovisno o načinu primjene upitnika. Oni su se $\mathrm{u}$ istraživanju koristili zavisnim uzorcima ispitanika koji su rješavali petofaktorski upitnik ličnosti s vremenskim odmakom od tri tjedna. Dobivene su vrlo visoke pozitivne korelacije (u rasponu od 0,81 do 0,92 ), što dovoljno govori u prilog stabilnosti korištenih mjera kroz različite načine primjene. Rothstein i Goffin (2006) na temelju ovih rezultata zaključuju da je u selekciji kandidata opravdano koristiti se internetskim upitnicima.

Primarni je cilj istraživanja bio provjeriti ima li razlika u davanju socijalno poželjnih odgovora i u brzini odgovaranja između sudionika u neutralnom uvjetu i stvarnih kandidata za posao, kod kojih je zbog selekcijske situacije izraženija motivacija za boljom samoprezentacijom. Sekundarni je cilj bio provjeriti može li vrijeme latencije služiti kao indikator socijalno poželjnog odgovaranja. Novost je u ovom istraživanju korištenje online-upitnika kojem ispitanici pristupaju sa svoga osobnog računala. Takvom smo metodom nastojali maksimizirati ekološku valjanost istraživanja jer su prijave za posao internetom u današnje vrijeme vrlo česte. Ovim istraživanjem testirane su različite hipoteze opisanih teorijskih modela. Očekuje se da će kandidati u selekcijskoj situaciji davati više socijalno poželjnih odgovora u odnosu na ispitanike iz kontrolne skupine, a što se tiče brzine odgovaranja, također se očekuje značajna razlika među skupinama u skladu s jednim od suprotstavljenih teorijskih modela.

\section{METODOLOGIJA}

\section{1 Ispitanici}

U ispitivanju su sudjelovala 252 ispitanika s Filozofskoga fakulteta u Rijeci ( 94 u selekcijskom i 158 u kontrolnom uvjetu) u dobi od 18 do 40 godina. $U$ kontrolnoj su skupini sudjelovale 142 ispitanice $(90 \%)$ i 16 ispitanika ( $10 \%$ ) prosječne dobi 25 godina ( $S D=5,43)$. U selekcijskoj su skupini sudjelovale 63 ispitanice (67\%) i 31 ispitanik (33\%) prosječne dobi 29 godina (SD $=9,22$ ). Stručna sprema ispitanika u kontrolnoj i selekcijskoj skupini prikazana je u tablici 1 . 
Tablica 1. Stručna sprema ispitanika u kontrolnoj i selekcijskoj skupini

\begin{tabular}{|c|c|c|c|}
\hline Skupina & Stručna sprema & Broj ispitanika & Postotak (\%) \\
\hline \multirow{3}{*}{ Kontrolna } & Završena osnovna škola & 4 & 2,5 \\
\cline { 2 - 4 } & Srednja stručna sprema & 56 & 35,4 \\
\cline { 2 - 4 } & Viša stručna sprema & 29 & 18,4 \\
\cline { 2 - 4 } & Završen fakultet & 69 & 43,7 \\
\cline { 2 - 4 } & UKUPNO & 158 & 100 \\
\hline \multirow{3}{*}{ Selekcijska } & Završena osnovna škola & 6 & 6,4 \\
\hline & Srednja stručna sprema & 36 & 38,3 \\
\cline { 2 - 4 } & Viša stručna sprema & 19 & 20,2 \\
\hline & Završen fakultet & 33 & 35,1 \\
\hline & UKUPNO & 94 & 100 \\
\hline
\end{tabular}

Izvor: obrada autora

Tablica 1 sugerira da nema značajnih razlika u stručnoj spremi ispitanika u kontrolnoj $\mathrm{i}$ eksperimentalnoj skupini, a to je potvrđeno $i$ hi-kvadrat testom $(\chi 2=3.51 ; \mathrm{df}=3 ; p>0.05)$.

\subsection{Pribor}

U istraživanju je korišten sljedeći instrumentarij:

a) Skala samozavaravanja - Uravnoteženi inventar socijalno poželjnog odgovaranja (BIDR, Paulhus, 1991). Korištena je skraćena skala samozavaravanja iz hrvatske adaptacije Paulhusova BIDR-a (Milas, 1998), koja se sastoji od 12 čestica. Primjeri su čestica: Nikad ne zažalim za svojim prosudbama. i Bilo bi mi teško riješiti se loših navika. Zadatak je ispitanika na skali Likertova tipa od 1 do 5 odgovoriti u kojoj se mjeri opisano ponašanje na njega odnosi. Cronbach alpha pouzdanost skale u ovom istraživanju iznosila je 0.77.

b) Skala laži (L-skala) - Eysenckov upitnik ličnosti (EPQ, Lojk, 1979). Skala laži iz EPQ-upitnika sastoji se od 21 čestice, npr: Uvijek održim obećanje bez obzira koliko mi je teško. Zadatak je ispitanika bio procijeniti vrijedi li opisano ponašanje za njega ili ne. Ova je skala korištena jer dobro pokriva konstrukt upravljanja dojmovima (Fastić-Pajk, 2005) te je možemo smatrati drugim načinom mjerenja dimenzije upravljanja dojmovima, kako ju je definirao Paulhus (2002). Cronbach alpha pouzdanost skale laži u ovom istraživanju iznosila je 0.83 .

c) Opća i demografska pitanja. U uvodnom su dijelu ispitanici upisali podatke za dob, spol, stručnu spremu i e-adresu. Ispitanici u eksperimentalnoj skupini dodatno su upisali naziv radnog mjesta za koje se prijavljuju kako bi testiranje bilo vjerodostojnije.

d) Računalo s pristupom na internet. 
e) Programska skripta. Za potrebe ovog istraživanja izrađena je programska skripta (u programskim jezicima PHP/mySQL/HTML/CSS/SS), veličine 64 kb memorije. Skripta je „ugrađena" u kôd web-stranice i ima dvije važne funkcionalnosti, mjerenje vremena latencije za svaki pojedini odgovor i onemogućavanje višekratnog odgovaranja korištenjem tzv. „kolačića”.

Budući da skala laži ima gotovo dvostruko više čestica od skale samozavaravanja, redoslijed čestica definiran je tako da nakon dvije čestice iz skale laži slijedi jedna čestica iz skale samozavaravanja. Pitanja su prezentirana u konvencionalnom obliku, slično kao i u papirnatim upitnicima. Za potrebe je ovog istraživanja odabran klizaći dizajn ${ }^{4}$, a za davanje odgovora korišteni su izborni gumbi 5 vertikalno dizajniranim skalama za odgovaranje (tablica 2). Sadržaj odgovora i vrijeme latencije u ovakvom dizajnu istovjetni su onima u straničenom dizajnu ${ }^{6}$ ili klizaćem dizajnu s horizontalnim skalama za odgovaranje (Maliković et al., 2017).

Tablica 2. Klizaći dizajn s izbornim gumbima i vertikalno dizajniranim skalama za odgovaranje

\begin{tabular}{|c|c|c|}
\hline 1. Volim se družiti s prijateljima. & $\begin{array}{l}0 \\
0 \\
0 \\
0 \\
0\end{array}$ & $\begin{array}{l}\text { uopće se ne odnosi na mene } \\
\text { uglavnom se ne odnosi na mene } \\
\text { niti se odnosi niti se ne odnosi na mene } \\
\text { uglavnom se odnosi na mene } \\
\text { u potpunosti se odnosi na mene }\end{array}$ \\
\hline $\begin{array}{l}\text { 2. Najmanje jednom sam prihvatio/la } \\
\text { pohvalu iako sam znao/la da ju je ustvari } \\
\text { zaslužio netko drugi. }\end{array}$ & $\begin{array}{l}\circ \\
\circ \\
0 \\
0 \\
0\end{array}$ & $\begin{array}{l}\text { uopće se ne odnosi na mene } \\
\text { uglavnom se ne odnosi na mene } \\
\text { niti se odnosi niti se ne odnosi na mene } \\
\text { uglavnom se odnosi na mene } \\
\text { u potpunosti se odnosi na mene }\end{array}$ \\
\hline $\begin{array}{l}\text { 3. Znalo se desiti da sam uzeo/la više nego } \\
\text { što mi je pripadalo. }\end{array}$ & $\begin{array}{l}0 \\
0 \\
0 \\
0 \\
0\end{array}$ & $\begin{array}{l}\text { uopće se ne odnosi na mene } \\
\text { uglavnom se ne odnosi na mene } \\
\text { niti se odnosi niti se ne odnosi na mene } \\
\text { uglavnom se odnosi na mene } \\
\text { u potpunosti se odnosi na mene }\end{array}$ \\
\hline
\end{tabular}


Tablica 2 na lijevoj strani prikazuje prve tri tvrdnje, dok su na desnoj strani uz svako pitanje prikazane skale za odgovore s izbornim gumbima. Za svaku tvrdnju ispitanik je birao jedan od ponuđenih odgovora (odabir više odgovora na isto pitanje bio je onemogućen).

\section{POSTUPAK}

Ispitanici u kontrolnoj skupini elektroničkom su poštom dobili poveznicu za izravan pristup online upitniku, dok su ispitanici iz eksperimentalne skupine poveznicu imali u okviru oglasa za posao koji je objavljen na portalu posao.hr (grupi linkedin) ili na nekom od oglasa objavljenom na portalu www. bika.net. Svaki je ispitanik rješavao upitnik na osobnom računalu, a dizajn i sadržaj upitnika bio je identičan za sve ispitanike.

\section{REZULTATI I RASPRAVA}

U okviru je predradnji za korekciju ekstremnih vrijednosti $10 \%$ najbržih te $10 \%$ najsporijih vremena latencije izostavljeno i nadomješteno EM-algoritmom, koji opisuje Pigott (2001). Kao preduvjet za multivarijatnu analizu varijance (MANOVA) provedeni su Kolmogorov-Smirnovljevi testovi, kojima je utvrđeno da normalnost distribucije zavisnih varijabli ne odstupa značajno od normalne raspodjele, te Boxov $M$-test, koji je pokazao da su matrice varijance-kovarijance homogene. Korelacija skala samozavaravanja i laži iznosila je $r=0.44(p<0.01)$.

\section{1 Testiranje efekata skupine na vrijeme latencije i socijalnu poželjnost odgovora}

MANOVA-om su pronađene statistički značajne razlike na multivarijatnoj razini u zavisnim varijablama (Wilksov $\Lambda=0.88, F(4,247)=8.05, p<0.01$ ). Multivarijatni $\eta 2$ temeljen na statistici Wilks $\Lambda$ upućuje na povezanost eksperimentalne situacije i zavisnih varijabli, odnosno veličinu efekta, i iznosi 0.11. Na univarijatnoj razini potvrđene su razlike među grupama. Otkriven je statistički značajan efekt pripadnosti grupi na vrijeme latencije na skali laži $\left(\mathrm{F}_{1,250}=5.51, p<0.05\right)$, skali samozavaravanja $\left(\mathrm{F}_{1,250}=8.42, p<0.05\right)$, brutorezultatu na skali laži $\left(\mathrm{F}_{1,250}=27.25, p<0.01\right) \mathrm{i}$ brutorezultatu na skali samozavaravanja $\left(F_{1,250}=9.53, p<0.05\right)$. Vrijeme je latencije i na skali laži i na skali samozavaravanja bilo dulje u selekcijskoj situaciji nego u situaciji iskrenog odgovaranja, a isti se trend manifestirao i kod brutorezultata: ispitanici su u selekcijskoj situaciji na obje skale ostvarili veće brutorezultate u odnosu na ispitanike u kontrolnom uvjetu (tablica 3). 
M. Fiškuš, D. Švegar: Socijalno poželjno odgovaranje i vrijeme latencije u kontekstu selekcijskog... Zbornik Veleučilišta u Rijeci, Vol. 6 (2018), No. 1, pp. 1-12

Tablica 3. Deskriptivni podaci za vrijeme latencije (ms) na skalama laži i samozavaravanja (u milisekundama) i bruto rezultati na skalama laži i samozavaravanja

\begin{tabular}{|c|c|c|c|c|}
\hline \multirow{2}{*}{ Upitnik } & Grupa & Prosjek & SD & N \\
\hline \multirow{2}{*}{ Skala laži } & Kontrolna & 119309,30 & 20121,28 & 158 \\
\cline { 2 - 5 } (vrijeme latencije) & Selekcijska & 125653,72 & 21790,01 & 94 \\
\cline { 2 - 5 } & Ukupno & 121675,87 & 20943,20 & 252 \\
\hline \multirow{2}{*}{$\begin{array}{c}\text { Skamozavaravanja } \\
\text { (vrijeme latencije) }\end{array}$} & Kontrolna & 65739,39 & 11859,54 & 158 \\
\cline { 2 - 5 } & Selekcijska & 70274,62 & 12224,99 & 94 \\
\hline \multirow{2}{*}{ Skala laži } & Kkupno & 67431,10 & 12172,88 & 252 \\
\cline { 2 - 5 } & Selekcijska & 74,23 & 10,40 & 158 \\
\cline { 2 - 5 } & Ukupno & 69,86 & 10,35 & 94 \\
\hline \multirow{2}{*}{ Skala } & Kontrolna & 37,57 & 10,91 & 252 \\
\cline { 2 - 5 } & Selekcijska & 40,28 & 6,35 & 252 \\
\hline
\end{tabular}

Izvor: obrada autora

$U$ tablici 3 vidljive su veličine razlika među aritmetičkim sredinama skupina kao i varijabiliteti rezultata. Dobiveni su efekti eksperimentalne skupine na vremena latencije u skladu s teorijom koja podrazumijeva da veća potreba za davanjem socijalno poželjnog odgovora rezultira duljim vremenom latencije (Nowakovska, 1970). Ta teorija pretpostavlja trofazni mehanizam koji obuhvaća doziv informacija, oblikovanje te evaluiranje odgovora. Taj se mehanizam u cijelosti aktivira samo pod uvjetom povišene motivacije za davanjem socijalno poželjnog odgovora, odnosno u ovom slučaju u selekcijskoj situaciji, dok u kontrolnoj situaciji nema potrebe za kognitivnim procesiranjem svih triju faza obrade tijekom davanja odgovora, pa je zato u neutralnom uvjetu odgovaranje brže.

Budući da Eysenckova skala laži (L-skala) mjeri disimulaciju odgovora kod ispitanika koji su motivirani prikazivati se boljima, poželjnijima i kompetentnijima (Lojk, 1979), kandidati za posao bi na njoj trebali postići veće rezultate od onih ispitanika koji upitnik rješavaju bez motivacije da se prikažu boljima. Takvi su rezultati i dobiveni i oni su u skladu s nalazima prethodnih istraživanja (Parmač et al., 2009; Proroković et al., 2008, Rosse et al., 1998). Rezultati na skali samozavaravanja također su povišeni kod kandidata u selekcijskoj situaciji. Taj nalaz nije u skladu s teorijskim modelom socijalno poželjnog odgovaranja koji je postavio Paulhus (2002), no taj model ionako nije potvrđen ni u ostalim istraživanjima (Pauls, Crost, 2005). 


\section{2 Vrijeme latencije kao samostalni indikator socijalno poželjnoga odgovaranja}

Diskriminantnom analizom provjereno je može li se selekcijsku i kontrolnu grupu razlikovati samo na temelju vremena latencije na dvjema skalama. Dobivena diskriminantna funkcija (DiF) pokazala je da prediktori statistički značajno diferenciraju ispitanike različite grupne pripadnosti (Wilksov $\left.\Lambda=0.97, \chi 2=8.28, p<0.05, \mathrm{Rc}^{2}=0.3\right)$. Na temelju ovih dvaju prediktora moguće je uspješno klasificirati $61,5 \%$ ispitanika u uzorku.

Rezultati ove diskriminantne analize sugeriraju da bi se vrijeme latencije per se moglo upotrebljavati čak kao indikator socijalno poželjnog odgovaranja. Ovome u prilog govore i rezultati o statistički značajnoj povezanosti vremena latencije na skalama laži i samozavaravanja s brutorezultatima na istim skalama, koja iznosi $r=0.19(p<0.01)$ za skalu laži i $r=.18(p<0.01)$ za skalu samozavaravanja. Ovaj rezultat, međutim, nije dovoljan za donošenje tako kontroverznog zaključka, ali može poslužiti kao polazište za buduća istraživanja.

\section{3 Metodološka ograničenja i nedostaci}

$\mathrm{S}$ ciljem je izbjegavanja problema diferencijalnog transfera u ovom istraživanju korišten nacrt $\mathrm{s}$ nezavisnim skupinama ispitanika koji onemogućava kontrolu određenih aspekata odgovaranja poput razlike u brzini čitanja kod ispitanika, iskustvu u ispunjavanju upitnika i razlika u osobinama ličnosti koje mogu korelirati s faktorom socijalne poželjnosti. Skala laži, naime, statistički značajno pozitivno korelira s dimenzijom savjesnosti, a skala samozavaravanja s dimenzijama ekstraverzije, otvorenosti i emocionalne stabilnosti (Fastić-Pajk, 2005). Zato je važno skrenuti pozornost na sadržaj određenih čestica koje bi mogle iskriviti interpretaciju na skali samozavaravanja. Na primjer, ljude koji su po prirodi introvertirani ne zanima što drugi ljudi misle o njima, a u kontekstu socijalne poželjnosti takvo se ponašanje smatra samozavaravanjem. Isto tako, izrazito ekstravertirani i poduzetni pojedinci obično su uvijek vrlo sigurni u svoje sposobnosti, a u kontekstu je samozavaravanja takva tvrdnja pokazatelj da osoba daje socijalno poželjan odgovor. Prema tome, važno je biti oprezan u interpretaciji rezultata na skalama socijalne poželjnosti koje bi se idealno trebale koristiti kao kontrolne varijable u većim baterijama, zajedno s upitnicima ličnosti, a u istraživanjima poput ovoga bi ih bilo poželjno statistički kontrolirati kao kovarijat.

\section{ZAKLJUČAK}

Zbog značajnog porasta upotrebe računala i interneta važno je prilagoditi način selekcije kandidata vodeći računa o ekonomičnosti i pristupačnosti ciljnoj skupini. U tom je kontekstu značajan doprinos ovog istraživanja, koje je pokazalo da više socijalno poželjnih odgovora daju kandidati koji su više motivirani prikazati se u socijalno poželjnom svjetlu. Što je još zanimljivije, vrijeme latencije pokazalo se kao adekvatan prediktor na temelju kojega možemo razlikovati kandidate koji daju socijalno poželjne odgovore od onih koji to ne rade. Dobiveni rezultati upućuju na potrebu za daljnjim istraživanjima u svrhu provjere mogućnosti korištenja vremena latencije kao dodatnog indikatora simulacije odgovora na upitnicima koji se koriste u procesima selekcije ljudskih resursa. 


\section{LITERATURA}

Bartram, D., Brown, A. (2004) „Online testing: Mode of administration and the stability of OPQ 32i scores”, International Journal of Selection and Assessment, 12(3), p. 278-284.

Fastić-Pajk, I. (2005) Socijalno poželjno odgovaranje u različitim modalitetima prezentacije čestica i njegova povezanost s osobinama ličnosti, diplomski rad, Zagreb: Odsjek za psihologiju Filozofskog fakulteta u Zagrebu.

Gur, R. C., Sackeim, H.A. (1979) „Self-deception: A concept in search of a phenomenon”, Journal of Personality and Social Psychology, 37(2), p. 147-169.

Holden, R.R. et al. (1992) „A model of personality test item response dissimulation” Journal of Personality and Social Psychology, 63(2), p. 262-279.

Holtgraves, T. (2004) „Social desirability and self-reports: testing models of socially desirable responding” Personality and Social Psychology Bulletin, 30 (2), p. 161-172.

Krahé, B. (1989) „Faking personality profiles on a standard personality inventory” Personality and Individual Differences, 10(4), p. 437-443.

Leary, M. R., Kowalski, R. M. (1990) „Impression management: A literature review and two-component model” Psychological Bulletin, 107(1), p. 34-47.

Lojk, L. (1979) „EPQ: Eysenckov upitnik ličnosti (Priručnik)” Ljubljana: Zavod za produktivnost dela.

Maliković, M., Švegar, D., Šomođi, S. (2017) „Utjecaj vizualne orijentacije skale za odgovore i broja stranica web-upitnika na rezultate ispitivanja" Zbornik Veleučilišta u Rijeci, 5(1), p. 1-12.

Milas, G. (1998). Korelacijska i eksperimentalna studija odnosa temeljnih dimenzija društvenih stavova, ličnosti i društvene poželjnosti, doktorska disertacija, Zagreb: Odsjek za psihologiju Filozofskog fakulteta u Zagrebu.

Nowakowska, M. (1970) „A model of answering to a questionnaire item” Acta Psychologica, 34, p. 420-439.

Parmač, M., Galić, Z., Jerneić, Ž. (2009) „Vrijeme latencije kao indikator iskrivljavanja odgovora na upitnicima ličnosti” Suvremena psihologija, 12(1), p. 43-60.

Paulhus, D. L. (1991) „Measurement and control of response bias“ In J.P. Robinson, P.R. Shaver, L.S. Wrightsman (Eds.), Measures of personality and social psychological attitudes (p. 17-59), New York: Academic Press.

Paulhus, D. L. (2002) „Socially Desirable Responding: The Evolution of a Construct“ In H. I. Braun, D. N. Jackson, D. E. Wiley (Eds.), The Role of Constructs in Psychological and Educational Measurement (p. 49-69), Mahwah, NJ: Erlbaum.

Pauls, C. A., Crost, N. W. (2005) „Effects of different instructional sets on the construct validity of the NEO-PI-R” Personality and Individual Differences, 39(2), p. 297-308.

Pigott, T. D. (2001) „A Review of Methods for Missing Data” Educational Research and Evaluation, 7(4), p. 353-383.

Ployhart, R. E., Lim, B. C., Chan, K. Y. (2001) „Exploring relations between typical and maximum performance ratings and the five factor model of personality" Personnel Psychology, 54(4), p. 809-843.

Proroković, A., Slišković, A., Bumbak, I. (2008) „Osobine ličnosti i socijalna poželjnost u selekcijskoj situaciji” Društvena istraživanja, 17(6), p. 1157-1177.

Rosse, J. G. et al. (1998). „The impact of response distortion on preemployment personality testing and hiring decisions” Journal of Applied Psychology, 83(4), p. 634-644.

Rothstein, M. G., Goffin, R. D. (2006). „The use of personality measures in personnel selection: What does current research support?" Human Resource Management Review, 16(2), p. 155-180

Salgado, J. F. i Moscoso, S. (2003). „Internet-based personality testing: Equivalence of measures and assesses' perceptions and reactions" International Journal of Selection and Assessment, 11(2/3), p. 194-205.

Smith, D. B., \& Ellingson, J. E. (2002) „Substance versus style: A new look at social desirability in motivating contexts” Journal of Applied Psychology, 87(2), p. 211-219. 
M. Fiškuš, D. Švegar: Socijalno poželjno odgovaranje i vrijeme latencije u kontekstu selekcijskog... Zbornik Veleučilišta u Rijeci, Vol. 6 (2018), No. 1, pp. 1-12

Sudman, S., Bradburn, N. M., Schwarz, N. (1996) Thinking about answers: The application off cognitive processes to survey methodology, San Francisco: Jossey-Bass.

Zuckerman, M. et al. (1995) „Hypothesis confirmation: The joint effect of positive test strategy and acquiescence response set" Journal of Personality and Social Psychology, 68(1), p. 52-60. 


\title{
SOCIALLY DESIRABLE RESPONDING AND LATENCY TIME IN THE CONTEXT OF SELECTION PROCESS FOR EMPLOYMENT ${ }^{3}$
}

\begin{abstract}
Socially desirable responding is defined as a systematic tendency of giving overly positive self-evaluations and is often manifested during a selection process. The aim of this study was to explore whether there was a difference in giving socially desirable responses and in the speed of responding between job applicants and a control group of subjects. The sample comprised 252 participants altogether. The experimental group encompassed 94 candidates applying for a job through a professional social network (www.linkedin.com) and a local website (www.bika.net) where available jobs were advertised, while in the control group there were 158 participants, who were answering the same questions as the job applicants. The web questionnaire consisted of 36 items from the Eysenck's Lie-Scale and Paulhus's Self-deception scale. Multivariate analysis of variance established that job applicants gave more socially desirable responses and responed slower than the control group participants. The results obtained by discriminant analysis suggested that latency time might be used as an indicator of socially desirable responding. Implications and suggestions for future research were also considered.
\end{abstract}

Key words: socially desirable responding, selection process, latency time, web questionnaire

MS in Psychology, Faculty of Humanities and Social Sciences in Rijeka, Sveučilišna avenija 4, 51000 Rijeka, Croatia. E-mail: matejfiskus@gmail.com

2 PhD, Posdoctoral Researcher, Faculty of Humanities and Social Sciences in Rijeka, Sveučilišna avenija 4, 51000 Rijeka, Croatia. E-mail: domagoj.svegar@ffri.uniri.hr

3 Received: 10 October 2017, Accepted: 15 December 2017 